\title{
New models of apprenticeship and equal employment opportunity. Do training networks enhance fair hiring practices?
}

\author{
Christian Imdorf \\ Institute of Sociology, University of Basel, Switzerland
}

Regula Julia Leemann

School for Teacher Education, University of Applied Sciences Northwestern Switzerland, Switzerland

\begin{abstract}
This study investigates whether occupational training networks enable the selection of apprentices to be less discriminatory. Training networks are a new organisational form of VET that is becoming increasingly widespread in Switzerland, as well as in Germany and Austria. In the Swiss model, an intermediary lead organisation recruits the candidates. It also attends to the apprenticeship itself and effects a placement of the young adults with the training network companies every year anew. The study is based on the sociology of conventions, which allows organisational mechanisms of selection in training institutions to be understood and the dangers of discrimination harboured therein to be appreciated. Based on a case study of a medium-sized training network, the study shows how this form of organisation permits a fairer selection, i.e. one that is gauged more by performance and less by social attributes of the applicants, as compared to selection processes in single SMB.
\end{abstract}

Keywords: apprenticeship; training networks; equal employment opportunity, Switzerland

This is an electronic version of an article published in

Imdorf, Christian \& Leemann, Regula J. (2012). New models of apprenticeship and equal employment opportunity. Do training networks enhance fair hiring practices?, in: Journal of Vocational Education \& Training, 64(1), 57-74

The Journal of Vocational Education \& Training is available online at: http://www.tandfonline.com/doi/pdf/10.1080/13636820.2011.622445

Corresponding Author:

Dr. Christian Imdorf Institute of Sociology Petersgraben 27

4051 Basel

Switzerland

Tel. +416126728 82

Fax. +41612672820

christian.imdorf@unibas.ch 


\section{Introduction}

To remedy the lack of training vacancies in companies at the outset of the $21^{\text {st }}$ century and to forestall the problems encountered by school-leavers in their search for an apprenticeship, Swiss vocational education policy has aimed at augmenting the supply of apprenticeship positions. In this respect, the federal government has been furthering so-called training networks since 2004. Alongside traditional training companies and workshops, Swiss policies on vocational education have designated the training network itself as a location for the placement of vocational training opportunities.

A training network is defined as a pool of numerous companies aspiring to guarantee apprentices qualified occupational training at a number of specialised companies. During their apprenticeship, the apprentices switch their training company on a yearly rotational basis (cf Figure 1). The actual educational go-ahead for the training network is issued to an intermediary organisation, the so-called lead organisation (LO). This organisation recruits the apprentices and draws up the training contract with them. With this, the training companies pass responsibility for the apprenticeship over to the LO.

Figure 1. Structure of a Swiss training network and the rotation of apprentices

The furthering of shared training as implemented through Swiss policies on vocational education not only serves the public good of creating additional apprenticeship opportunities. This new educational form is also a reaction to changes in the educational requirements made of companies: rising flexibilisation, the rationalisation of production processes and the standardisation of products mean that 
small companies in particular are only able to provide training to a certain extent, i.e. only in part. Shared training enables such companies to continue to offer training or to set up a company training scheme. On the one hand, the training networks evolve bottom-up, in the sense that various companies get together, name a lead organisation and regulate their cooperation by contract. On the other hand, they also evolve topdown, in that state or private actors (for example, trade associations) deploy a LO, which recruits training companies that show interest in the scheme.

Shared training by means of these networks is a particularly attractive option for many training companies; the LO assists them significantly in providing the training services and the companies are freed from the responsibility for the apprenticeships themselves. The services of the LO in which the training network companies are financially involved cover the administration of the apprenticeships, the support and monitoring of training network companies and the apprentices (including advising and assistance with training problems at part-time vocational school or in the company as well as controlling educational objectives), taking on training assignments and organising rotation. Not least, the LO recruits the apprentices of the entire training network and thus relieves the individual companies from selecting new apprentices themselves, a procedure that is time-consuming and fraught with risk. It is often the case that the small training companies are poorly equipped to deal with recruitment since they lack the professional know-how, reliable selection instruments and indeed the time for selection itself (Imdorf 2010a).

The present paper investigates the repercussions of this organisational form of training networks on the selection of apprentices. Thereby we focus on the consequences of 'outsourcing' apprentice selection procedures, away from the companies to the LO, for a fair placement of apprentices. Of specific interest here is 
the relevance of the recruitment process in training networks for youth who are labelled 'foreigners' and who are most severely affected by exclusion from incompany vocational training in Germany and Switzerland (Imdorf 2010c). School graduates are seen as 'foreigners' in many recruiting processes when they hold a family name, nationality, biography or mother tongue referring to an origin from certain countries perceived as alien and devalued in public such as former Yugoslavia (in Switzerland) or Turkey (in Germany), or when their appearance (headscarf, skin) indicates that they belong to non Christian religions (e.g. Muslim). ${ }^{1}$

Up to now, the question of equality of opportunity in the selection of apprenticeships by way of training networks has barely been raised. The educationally motivated initiatives for creating more training places with the training networks do not question whether or not all those seeking training actually benefit equally from the scheme. Our explorative case study will culminate in the hypothesis that training networks, as opposed to traditional training companies, render greater fairness in the award of apprenticeships because of the specific organisation of training and selection procedures.

Since to date there are hardly any scientific findings about the placement of apprentices through the training network, a brief outline of the research will first sum up the criteria that structure the selection of apprentices in traditional training companies. Reference will be made to the French sociology of convention that enables to analyse selection procedures both in single companies and training networks as well as the phenomenon of discrimination in the allocation of training places. Based on a case study, the empirical part will focus on reconstructing the manner in which a training network, commissioned by the state to integrate disadvantaged school-leavers, selects apprentices and allocates them to training 
companies, which hardly have any idea themselves of this commitment to society. The final part sums up the case study, systemises our hypothesis and points to issues that still call for further research.

\section{Research overview and theory}

\section{Criteria for the selection of apprentices}

Up to now, German and Swiss evaluation research on training networks has produced very little about the issue of recruitment and selection. According to an evaluation carried out by the Swiss Federal Office for Professional Education and Technology (BBT 2008, p. 11), three-quarters of all apprentice recruitment runs over the LO alone. The apprentices are then allocated to the various training network companies, which in general have a right of veto. The recruitment pool of would-be apprentices depends on the specific orientation of the training network. There are some that recruit young people directly after they have completed their compulsory schooling. There are others, however, who give preference to those who have completed transitional, tide-over measures (ibid., p. 9). Hence thanks to the training networks, training and developmental options are open to those who are less able, as well as to the high achievers (Walther \& Renold, 2005). A survey from Germany shows that German training network diploma holders tend to have a lower secondary school qualification rather than eligibility for higher education as against the control group of apprentices in traditional trade apprenticeships (BMBF 2004, p. 144f). This gives rise to the assumption that training networks can be of particular help to disadvantaged school-leavers in procuring an apprenticeship. One possible explanation might be that the LO acts as an intermediary organisation and, by linking employers and young apprenticeship seekers, enhances the social capital of the latter (Strathdee 2003). 
There are, however, no empirical data available showing to what extent training networks manage to better integrate disadvantaged youth than traditional training companies do.

Whereas actual selection criteria applied by training networks have hitherto hardly been subject to any investigation, results from a number of studies are available on the selection process in traditionally organised training companies. Those studies indicate the high priority placed on school results in large enterprises (Moser 2004) and the 'personal impression' made by the candidate in general (Schmid \& Storni, 2004; Stalder 2000). Two older studies on discrimination in hiring apprentices (Lee \& Wrench, 1983; Schaub 1991) reveal that personnel managers question both the staff's willingness to accept 'foreign' youth as well as the latter's willingness to integrate into the staff and to subordinate to their supervisors. Managers furthermore expect higher dropout rates when hiring 'foreigners' as apprentices. Our recent study of the selection of apprentices in small and medium-sized businesses shows that the award of training places primarily follows a logic of 'suitability for the company', one that attempts at an early stage to shield the company from the risk of incurring difficulties with recruited apprentices (Imdorf 2008). Hence, during the recruitment process, candidates have to convince personnel managers that they will neither disturb the horizontal and vertical social relations at the workplace nor existing customer relations. The selection process furthermore focuses on school reports to ascertain whether or not the candidates are in a position to satisfy the minimum requirements of the part-time vocational school (Imdorf 2009).

Yet companies are not only looking for apprentices whose training will occasion as few problems as possible. The selection process itself should not be such as to bind too many resources. Seen from this angle, in contrast to the small and 
medium-sized businesses, school qualifications take on an enhanced pre-selective priority with the larger enterprises, given the larger number of applicants and the fact that companies rely on low-cost methods for early selection. However, with small and medium-sized businesses, pre-selection procedures applied right at the outset feature criteria of social matching, controllability and leadability along with customer preferences so that the allocation of training places is also shaped by discriminating categories, such as the stigma attached to being 'foreign' or to gender and age (Imdorf 2010a, 2010c). By contrast, in the large enterprises featuring a greater degree of formalisation in the allocation of training vacancies, job candidates are very likely to be protected from such forms of company discrimination (Seibert, Hupka-Brunner \& Imdorf, 2009).

\section{Selection in training networks from the perspective of pragmatic sociology}

Previous research on the recruitment of apprentices has lacked the appropriate theoretical foundations to satisfactorily explain the exclusion of disadvantaged school-leavers from training companies. On the one hand, research has been too much guided by public opinion, which emphasizes the relevance of school certificates for the success of candidates. On the other hand, the perception of candidates along the narrow lines of assumed individual productivity (characteristic of economic theories of personnel recruitment) disregards the complex social relations and dependencies within the company. Hence, the investigation of selection processes in training networks calls for a theory by which personnel selection and discrimination can be understood and which also does justice to the complex organisational structure and forms of coordination of training networks. The French sociology of convention resolves both claims. This embodies a trandisciplinary approach, established in French economic sciences as well in French sociology and is founded on the 
pragmatic sociological theory of Boltanski and Thévenot (2006); it integrates a number of the special fields of sociology (including economic sociology, the sociology of labour and organisational sociology) on the basis of a pragmatic theory of action (Diaz-Bone 2009). The core element is the observation and analysis of the forms by which people coordinate concrete action among themselves or with their environment, as well as the conventions contributing to the shaping of a common ground of perspectives, thus making it possible to coordinate and justify action (Dodier 1993). The term conventions denotes collectively established cultural forms, such as are structured, evaluated and legitimised in relationships between several actors. The evaluation of the 'quality' of one actor is based on conventions in varying contexts of coordination with a unique principle of order and justice to which Boltanski and Thévenot (2007, p. 183) refer as 'worlds' (cf. Imdorf 2008, for application of the concept of worlds to the allocation of training places).

The central conventions of the economic system, not least the recruitment of new employees and apprentices, are deemed to be the industrial, market, domestic and network-based conventions (in the following we refer to Diaz-Bone 2009, p. $242 \mathrm{f}$ for an outline of these conventions). The industrial convention pursues the principle of medium and long-term planning of action for which resources are to be used productively. The flows of action are accordingly gauged in line with an efficient organisation of work. Work methods, work relationships and products are standardized and accordingly the actors' 'quality' is assessed by the degree of productivity in their contribution to the manufacture of products and services. In this 'industrial world', performance is the justifying principle. The selection of apprentices is very much governed by future production sequences being supported and as far as possible not disrupted by professional and educational abilities. 
By contrast, the market convention accentuates the relational principle of price and competition within a short-term time window: among other factors, economic cost-benefit analyses of the network partners may well be relevant to the cooperation between the LO and the companies of a training network. The nature of the relationship between the actors is strategic and coordination is aligned opportunistically to the market situation. An actor himself reflects 'quality' either as solvent purchasing power or by providing a commodity much in demand yet in limited supply (as seller). In terms of the selection of apprentices, this market logic means that a future apprentice in the 'market-driven world' is as conducive as possible to the sale of a product or service and does not obstruct it. In direct contact with clients, the apprentice hence embodies a market value so that, because of customer preferences, social features may well be of relevance in selecting personnel (Becker 1971, p. 75f).

Against the setting of the domestic convention, an actor reflects 'quality' if trust is placed in a person on the grounds of his or her 'social proximity', circle of friends, relatives and personal relationships. The worth of the apprentice is accordingly measured in terms of the person's trustworthiness and dependability, loyalty and 'character'. Contrary to the first two aforementioned conventions, the time perspective in the domestic convention tends to hinge on tradition and hence on the past. In their selection procedure in the 'domestic world', training companies invoke this convention if they are seeking to have as matching and as compatible a workforce as possible in their company. The discrimination against 'foreign' applicants is specifically an outcome of selection in the domestic world (Imdorf 2008).

Whereas placement with small and medium-sized businesses under the three abovementioned conventions can largely be understood (Imdorf 2010c), the network 
structure of training networks obviously points to considering the so-called network convention when investigating selection processes. This convention constructed by Boltanski and Chiapello (2005) allocates 'quality' to actors if they form networks, dispose of flexibility, mobility and a readiness to take risks and if they prove to be 'project-capable'. Unlike the form of relationships in the domestic world, relationships in the 'project-type world' are lived flexibly and for restricted periods of time, i.e. social bonds and friendships are only of relative or moderate duration in the time perspective of this convention. For this reason, with the placement of apprenticeships in training networks, the network convention could be significant since such project-related 'qualities' are possibly required from the apprentices, given their yearly rotation between the training companies. Up to now, we are aware of no research findings according to which companies' expectations of flexibility are coupled with categories of discrimination (e.g. on the grounds of ethnicity).

From the angle of the training system, the 'civic world' propagated by Boltanski und Thévenot (1999, p. 372) also needs to be considered in order to appreciate the placement of apprentices in the training network. Its civic convention is founded on a collective interest and claims a social contract, which restricts selfcentred, company-own interests by way of its commitment to a common good (Imdorf 2008, p. 126). In structuring relationships, it is the principle of equal opportunities that leads. From the very outset, the civic norm requires the companies to abide by the law. Since, however, as opposed to the structuring of the apprenticeship, the state hardly regulates a company's selection of apprentices at all, the civic convention has only a very slight effect on structuring placement procedures. However, for placement procedures in those training networks in which the state played a part, either in initiation of the network or with funding from the public sector, it is likely that the 
civic convention is of relevance. In such a setting, a training network usually has a civic contract to fulfil, one that also expects disadvantaged groups to be considered for recruitment.

The conventions outlined can be viewed as major principles of relationships in the context of a training network guaranteeing the coordination of reciprocal expectations and requirements between the actors LO, training company and apprentice. As principles of equivalence and justification, they provide at the same time the basis for the evaluation and selection of new apprentices.

The phenomenon of discrimination can be understood in the light of pragmatic sociology, whereby differentiation has to be made between two processes, which independent of one another both lead to organisational discrimination (cf. further details Imdorf 2010a). On the one hand, the selection of apprentices generates discrimination if the company selection process is not primarily driven by the industrial world's requirements for performance. In that case, meritocratic justification is no longer given if the conventions and the expectations of the domestic and the market world are asserted, i.e. the motive of enhancing social company integration and customer ties. On the other hand, discrimination can also be the result of a 'gauging problem' with selection. Successful applicants have to provide evidence of their 'quality' in multiple worlds and pass numerous 'reality tests' (cf. Imdorf 2008 for empirical examples). Discrimination evolves in such test runs if an applicant's 'quality' for the company is assessed based on bias toward certain groups (e.g. based on gender or age) or on processes of social attribution in order to accelerate selection procedures and hence keep them cost-effective (Eymard-Duvernay \& Marchal 1997; Jewson \& Mason 1986). As against the motives of selection, reference is made to Reskin (2003) who stresses the mechanisms of discrimination. It is only specific 
forms of organized selection procedures that allow those responsible for personnel to incorporate their discriminating stereotypes into the process. The application of the discriminating selection criteria of the domestic or the market world also requires a procedure that admits discrimination in the first place. For example, a recruitment procedure often characteristic of small companies that is based on social network recruiting makes it easier for the domestic world to apply its selection criterion of social matching (Jenkins 1984).

In the light of this theoretical framework, the following is to establish which conventions determine the structuring of apprentice selection in a training network. On the other hand, analysis is also to focus on the extent to which the organisation of the selection procedure of a training network as opposed to selection in conventional training companies is likely to better prevent discriminating company expectations from evolving. These two research questions are discussed empirically by way of a case study. In concrete terms, investigation is to focus on what it is that enables a specific training network to satisfy its social commitment to the integration of disadvantaged school-leavers and place them with training network companies, which themselves hardly have any knowledge of this societal contract.

\section{Case analysis: method and portrait of the selected training network}

\section{Method}

In order to answer the questions under investigation, an explorative case study of a training network was conducted. A single case study is appropriate to the research project since the training network constitutes a critical case (Yin 2009, p. 47) of an educational and training organisation when it comes to selecting apprentices for the dual system of education and training. To what extent the known differences in 
selection criteria between large enterprises and small companies can be transposed to a training network is unclear, for in the light of its own structure, the training network features an interesting form of compromise between the features of the small and the large company. In the case investigated, the network first and foremost incorporates small and mini-sized companies parallel to a few large enterprises. Not only this, the personnel administration and apprenticeship support covered by the LO is not dissimilar to the educational and training organisation of a large enterprise. There too, apprentices are centrally recruited and administered to then complete their training in various departments of the enterprise. Contrary to both large and small training companies, the responsibility for training in a training network does not, however, lie with the companies themselves but with the LO. For this reason, by way of the example of one training network, the extent to which the known selection criteria of small companies and large enterprises can be transposed to this new form of training is to be clarified and the extent to which the currently available scientific insights on the placement of apprentices needs to be expanded in order to understand the selection for apprenticeships within a training network.

Since the data material stems from an evaluation study and was reanalysed for the issues of the current investigation, the case study here is a secondary analysis. The evaluation $^{2}$ embodied semi-structured interviews with differentiated questioning that includes the subjects of selection and rotation; consideration was also given to the heterogeneous perspectives of actors within the training network under review. The data material covers a total of nine interviews: two with the manager of the LO and with an employee who is responsible for apprentice administration and who assisted with pre-selection; two interviews were held with three so-called training coordinators; in legal terms these are the duly authorised 'training supervisors' who 
attend to the apprentices and check their training progress at the LO; finally, five interviews were held with eight trainers who are responsible for the briefing and training of the apprentices in various training network companies (in two homes for the disabled, two child day care centres, two homes for the elderly and in a training company $^{3}$ for IT technicians and electricians).

The data from the evaluation study hence allows analysing recruitment and selection processes - though not their outcomes - in training networks based on an explorative, single-case study design with multiple units of analysis (LO and training network companies; cf. Yin 2009, p. 47 for embedded single-case design). The various perspectives of the selection enable an adequate appreciation of the placement of apprentices in a training network. By means of a qualitative analysis of the transcribed interview material, both the selection procedure (mechanism) and the conventions (motives) on which recruitment and apprentice selection are founded were reconstructed.

\section{Portrait of the investigated training network}

The training network analysed was initially set up as a registered association in reaction to the serious lack of apprenticeships in German-speaking Switzerland during the late 1990 s by a municipal occupation information centre. At the outset, training only focused on office administration. In the following years, the number of apprentices and training network companies continued to rise and the occupational options on offer expanded. In the year 2006, with the help of a capital investment from the local council, the association was converted into a non-profit trust and disengaged from municipal administration. A central aim of the trust, as set down in its statutes, is to integrate young adults who are at a social disadvantage (women, 'foreigners', socially disadvantaged groups) into working life. Integration was to be 
effected by expanding the apprenticeship options on offer and by working together with private and public companies. The trust is financed from the subscriptions paid by the training companies, including municipal funds - during the pilot phase with federal funds - and by means of specifically acquired donations from private companies. At the time the survey was conducted in $2007 / 2008$, the network had up to 180 training places for the qualified occupations of office administrator, IT technician, electrician and carer on offer in some 130 companies. Training network companies are also small and mini-sized companies that without the collaborative training venture would have no chance or would not be prepared to offer training themselves. The new three-year training programme for qualified carers is particularly dependent on training network apprenticeships; the job profile here is of a generalist nature and the apprentice spends one year training in each of the areas of childcare, care of the elderly and care of the disabled.

It is remarkable to note that in its own image profiling, the trust does not explicitly highlight its purpose, as do potential new training companies. In fact on its website, the training network rather emphasises the advantages of collaborative apprenticeships (including the opportunities for specialised companies, apprentice productivity, chance of the apprentice being subsequently employed on a permanent basis, low drop-out rate). Not only this, the potential training network companies are promised a selection process that is specifically tailored to their own job profiles.

\section{Analysis of the selection process from the perspective of pragmatic sociology}

Recruitment candidates are pooled, partly as a result of advertising the training places on the Internet over the cantonal apprenticeship portal. These measures are also enhanced by allocations to the training network made by an occupation information centre, placing school-leavers who have been unsuccessful in obtaining an 
apprenticeship but are assessed as being 'suitable for training' with a training network. Both groups undergo the same process of selection.

The selection procedures of the investigated training network as reconstructed from the interviews are broken down following recruitment into four stages: preselection of the application files, in-house tests, face-to-face interview and a short placement with the company. The following describes each of the steps of the procedure and interprets the selection criteria examined from a perspective of pragmatic sociology.

\section{Pre-selection of the application file (by LO)}

During the pre-selection phase, the written applications are first "roughly selected" (according to an IT training coordinator). In this procedure, paramount interest is on the qualified school track documented in the application file and the applicants' school marks and, for qualification in office administration, the results of external academic tests that have to be completed with private service providers. Focus of assessment is the question as to whether the standard of school performance meets the requirements set by the part-time vocational school for a qualified occupation. The training coordinator for information technology - a subject that can be quite challenging - was of the opinion: "There are some applications, I have to say, that as regards the level of education, well, it is impossible for it to work. These are the ones that are sure to be filtered out". Educational requirements here are subject to a convention directed at company-related and educational usefulness or efficiency: to fill an apprenticeship vacancy with someone who can conceivably be seen to come to grief with the requirements of the part-time vocational school would be tantamount to a false investment on the part of the training organisation. 
Given the municipal mandate of the training network to include disadvantaged school-leavers in apprenticeship placements, the LO also applies the civic convention in its pre-selection procedure. Particular attention is paid to applications from young adults who have already received a number of rejections in their search for an apprenticeship. In the eyes of the carer training coordinator, this does, however, make the task of selection more difficult: "On the one hand, we need good apprentices who turn out successfully. But we also have a social mandate from the town council that has to be satisfied." The interests of the industrial world (good school results) evidently conflict with those of the civic world (social integration). A compromise has to be found as regards the education-related logic of selection so as not to fall short of the objective of integration. According to the statements of the training coordinator for carers, such a compromise is found by focusing, each to one third, on "very good, good and under-achieving" adolescents.

With young people who apply for the qualified occupation of carer, attention is also paid to information in the application file about completed internships, leisure activities or parents' occupations in order to deduce social competencies that are likewise pre-selective in character. The social competence required as selection criterion for social occupations embodies the requirements of professional service relations to which a compromise of market and - depending on the timeframe of the social relationship - domestic or project-type logic is allied (Imdorf 2008, p. 156f). It is noticeable that with the pre-selection procedure of the investigated training network, the specific criteria (such as origins or gender) of social company fit play no role at all as compared to the early selection criteria known to exist in small and medium-sized businesses. 


\section{“Test half-day" (in-house tests of LO)}

The candidates selected on the grounds of their written applications then undergo a "test morning or afternoon" when they take diverse in-house aptitude tests. The tests used are an interest test from the occupation information centre and the intelligence test PSB-R-6-13 (test system for school and education counselling for the $6^{\text {th }}$ to $13^{\text {th }}$ classes). In addition, the candidates are required to write an essay on the subjects, "Who am I? - Me in five years' time - My family - Why this particular occupation?" (carer training coordinator). The interviews with the training coordinators show that besides providing indication of the occupations in which the applicant is interested, the in-house tests first and foremost aim at confirming or supplementing the relatively unreliable school assessments documented in the application file. This makes it possible to compare the educational standards of the various applicants ("We need to have a measure by which we can compare the applicants") and to reliably forecast educational ability (“... and to predict (...) that they [the apprentices] will be successful in their apprenticeship", carer training coordinator).

The in-house tests are reality tests subject to an industrial convention, for they are standardised, produce comparable results based on 'hard facts' and evoke an educational planability. As with the criteria applied in the pre-selection, these tests from the industrial world prevent the training companies' discriminating mindset of the domestic and market world from being asserted at an early stage.

\section{Face-to-face interview (LO)}

If the candidates prove successful during the 'test half-day', they are then invited to an interview with representatives from the LO. Whereas interviews in individual companies generally show whether or not a candidate fits the domestic world of the company (Jenkins 1984), the interview for apprenticeship placement with the 
investigated training network not only discloses motivation ("is the candidate now able to express that he wishes to train in this occupation and why?"), but is also a reality test for fitting into the system of the training network. In the words of the manager, "the flexibility that someone is also in a position to go to a number of locations" is an issue that is thus resolved. The coordinators see it as one of their "core competencies" to "ultimately somehow pick" a candidate "out of a group, when you can say 'he will prove himself", someone for whom you can "be responsible for sending him into several companies". Whether or not an adolescent can be expected to prove himself in the 'system' is decided by a "good gut feeling" (carer training coordinator) that one has. The IT training coordinator detailed clearly in a longer section just what, in concrete terms, the specific requirement of the training network 'system' actually means:

\begin{abstract}
"There [during the interview] you do get a little indication of whether this is someone with whom we can work or not. And we have to say that people who are apprenticed in a collaborative training venture have to meet criteria that are a little bit special. This is not about me recruiting apprentices myself for my company - 'can I imagine him in my company?' - but it is more like 'do I see him in the training companies we have?' And is it possible we can expect him to work in another company every year? Does he have the flexibility? Isn't he more someone who needs a bit of security, someone who is more of a reserved type, someone who you (...) have to build up a relationship with until he opens up?' In a training network this is almost impossible. It's more like those, what shall I say, who are brighter, as regards behaviour, but then this doesn't necessarily mean they are better educationally speaking" (IT training coordinator).
\end{abstract}

The quoted coordinator differentiates between 'fitting into the training network' (flexibility, openness) and fitting into the individual company. As voiced by the carer training coordinator, candidates of a "reserved type" need "a more stable setting", that allows for "a bonding with the company", something a training network cannot offer.

Moreover, according to the IT training coordinator in another section, the system gives "no space to anyone who somehow seeks to be invisible", because for such people the controlling options in a training network are inadequate. "Naturally, if this is someone who wants to, he could play off the trainer against me any day at all 
(...). We don't need people like that." With this, the organisational-spatial distance between LO and the training company and the associated difficulties in apprentice back-up are addressed. The most promising candidates for the apprenticeships are consequently those who are more trustworthy and "brighter". They do not have to be only the educationally good candidates so that the criterion of educational performance, which was of prominence in the preceding two stages of selection, is now relativised.

With the necessary competence of repeatedly adjusting to new social factors, i.e. living social relations project-like, the representatives of the $\mathrm{LO}$ relate to the 'project-based' convention of the coordination of action that takes off from a projectbased social structure of the working world. The principle of equivalence for the assessment and the comparison of persons in the project-type world embodies, in accordance with Boltanski (2007), the activity of incorporating oneself into projects initiated by others, overcoming one's own isolation and engaging in new encounters with other actors. In this world, the person with 'quality' is the one who proves to be adjustable and flexible and who clearly copes with a whole variety of situations. By contrast, those apprentices who are in danger of being excluded by the training network organisation are those who do not seek new contacts, "who do not know how to engage because they fail to inspire trust, who are unable to communicate because they are withdrawn", something that "is tantamount to being socially dead in the bright new network world" (ibid., section 8 - translation from German).

\section{Short internship in a training network company}

The training coordinators then send the successful candidates from the interview for a one-to-five-day placement in selected training network companies, trying to match apprentices and companies as realistic and as promising as possible. Two candidates 
are sent to a company, thus still ensuring that the latter has a choice. ${ }^{4}$ Remarkably the trainers do not receive any application documents to view ("I don't know the school marks, I don't know the background," trainer at a home for the elderly), i.e. the candidates are solely assessed during the brief placement on the grounds of observation and experience. As soon as a training network company considers an applicant to be suitable for training, the LO enters into a training contract with the applicant.

The interviewed trainers at the network companies reported that, during this brief placement, they above all concentrated on whether or not a candidate shows evidence of being able to fit into the company socially and whether the candidate showed "team ability". The trainer of a child day care centre paid attention too to "the general demeanour, in other words friendliness". For the trainer of a home for the disabled it is ultimately important that applicants show themselves to be authentic and "feel at ease". In this, the trainers are driven by the requirements of the 'domestic world', the fulfilment of which by the applicants is usually assessed affectively (Imdorf 2008, 2010b). The trainer responsible for training electricians put it this way: "And if we have the feeling 'it can work' and there's nothing special where one would have to say, 'No', then that's ok'.

The 'short day placements' furthermore give the company trainers the chance to assess the interests, motivation and work ethics of the young people. The trainers for carer occupations also check whether the young people show the social competence necessary for these service professions. In a child day care centre the right balance between "proximity and distance" in the initial contacts with the children in care is assessed. At the homes for the elderly, attention is paid to whether the future applicants "are able to establish contact with elderly people" and in a home 
for the disabled and at a day care centre, the older young adult is preferred to the direct school-leaver to ensure that neither apprentice nor persons in care are put to excessive strain.

The restricted scope of choice of the companies means that trainers at the training companies repeatedly have to compromise and also accept apprentices who would hardly have had any chance of an apprenticeship at all in the selection procedure of a single company. They justify the greater readiness to take on risks, and to choose someone who “doesn't come into question really" or who "you don't really know what you can expect in the summer" by arguing, that, within the scope of the rotation system, an apprentice only has to be trained for one year: "But well, I think the difference is still that you say: one year. One year is doable, even if it doesn't work out at all, whereas now with a three-year training I see things differently" (trainer at a child day care centre).

The manager of the training network affirms that because of the one-year training modus, the companies are able to relieve themselves of responsibility: "They [the trainers] say to themselves: 'Yes we have a certain responsibility for the year.' But whether this person develops, (...) whether he passes the final qualifying examination, that at the end of the day (...) is our [i.e. the LO] problem." The trainer of a home for the elderly also mentioned the care and support on offer from the LO that enables her to "attend to young adults without bias." For "if there are problems, I can turn to them [the training coordinators] (...). If you want to give a young person a chance, when you say about him, 'Yes, we are not quite sure', that's fine by me." The trainer from a child day care centre too pointed out that the higher degree of acceptance of "risk youngsters" gives those people a chance who "one would at first perhaps not accept at all." 
The restricted scope of choice given to the trainers in the training companies during the last stage of the selection procedure in combination with the responsibility for the apprentices over a restricted period of time, as well as the prospect of being able to count on the support of the training coordinators for problematic cases, lessens the companies' anticipation of problems and their aversion to risk in their confrontation with young adults who at first glance do not seem to them to be very reliable. This makes it easier to allow greater application of civic principles in the selection of the apprentices, without having to sacrifice them early on to company cost-benefit analyses.

\section{Assessment and manipulation of the selection procedure by the training network companies}

The selection procedure presented is assessed ambivalently, mostly positively, by the training companies. In application of the industrial convention, the trainer of a child day care centre clearly sees the advantages with regard to the yearly rotation procedure too: "It is good, the time input is small, meaning I have this person for one day. I don't need to look at ten people who somehow come for a week's placement. It saves me a great deal of time. I do not have to organise it, they are allocated to me" (trainer at a child day care centre).

The broad degree of acceptance of the restricted scope of choice calls for the trainers' trust in the pre-selection made by the LO. The trainer of electricians: "They actually do a relatively good pre-selection.” The trainer at a home for the elderly: "Since I am convinced that they really do a respectable selection procedure, I have to have reasons to say, 'No'; there really have to be grounds for me to do so." The trainer at home for the disabled: "They come, presented themselves for one day, we take them and up to now that has worked out." Only the IT trainer complained that the 
educational level of the allocated candidates sometimes left much to be desired. According to statements of the manager, such trust has developed in the companies and they know "that I am not just sending them anyone, where they have to shake their head" and have to say, "My God, have they completely lost it?" Maintaining trust is a delicate matter involving a number of different factors (How is the apprentice developing? Does the person fit into a company in future? How does a company react to problems with an apprentice? etc.).

There are some companies that would prefer to select candidates themselves to be quite sure of obtaining one that is suited to the company and the occupation. Sometimes criticism is voiced of the brevity of the short placement that hardly allows any time to get to know an apprentice and assess his or her aptitude on site. At the same time, the companies appreciate the challenge faced by the LO in distributing the pool of apprentices in their final selection and during the rotation to the various training network companies. The trainers in the companies understand that the organisation of this allocation with the selection and rotation procedures - a challenge for the LO in the industrial world - would hardly be feasible if the companies were to have a too great a say in the matter. Because of the largely positive experience with the pre-selection procedure of the training network, the companies accept this constriction so that it is possible to even recruit an apprentice who does not at first sight make a particularly convincing impression.

Nevertheless, there are isolated cases when particularly the social institutions (carer training) undermine the selection procedure of the training network by attempting to introduce young adults known to them from previous internships. ${ }^{5}$

Trainer at home for the disabled: "I need good apprentices, I need, I want to choose them myself, who it is (...). And so I did not let them talk me into it. I have apprentices and next year I'll register them there, 'you [LO] had better take them.'” 
The calculated undermining of the official selection procedure meant that with the placement of well-known apprentices there was a risk reduction and additional benefit for the training company in the first year of apprenticeship. The manager criticises this given that such cases frequently show "that the personality indeed prevails but that, educationally, there's absolutely nothing whatsoever. Then we just have to say no. If we then say no, the company says, we are not cooperating."

The remark that the readiness to train and cooperate of individual training network companies could be endangered by asserting the official selection regulations indicates the market-driven compulsions of a training network. In allocating candidates and apprentices, the LO thus takes account of company preferences. The training coordinator for the carer occupations emphasises the matching of apprentice and company in the domestic and in the industrial world: "I look a little at the apprentice's personality. I look what kind of background there is, does he fit (into the company) in terms of personality. And as regards the standard, do they want someone who is very quick or can the company handle (someone) who is a bit slower or not so mature, and then I match up like that." At another place, she details the 'buffer function' of the LO between the civic requirements of the organizing institution and the market-driven demand of the training network companies:

\footnotetext{
"We bridge the gap between the training companies, the apprentices, the municipality, the occupation information centre and we have to do justice to all of them. And naturally our focus is on the apprentice but at the same time we don't want to lose the companies."
}

\section{Conclusion}

Training networks not only guarantee additional apprenticeships. They also make it possible to distribute them with greater fairness than the traditional companies have been able to do up to now - at least this is our propagated hypothesis. Hence, besides stabilising the dual system of educational and vocational training in times of 
globalisation and flexibilisation, the training networks may also contribute towards greater fairness in the placement of apprentices. However, evidence has yet to be produced that organising training in this way really does generate less discrimination than is the case with apprentice recruitment in traditional training companies. Even if the statements of those interviewed speak in favour of assuming that, owing to the way it is organised, the training network can be fairer with the placement of apprentices than conventional training companies are able to be (there were interviews pointing out that the apprentices had mostly been in transitional, tide-over measures, that they were of an above-average age, often came "from other cultural backgrounds" and in part had "slight disablements"), there is still no statistically validated evidence for our hypothesis for the moment.

Nevertheless, by way of a single case study, we have demonstrated how the organisational form of a training network affects the selection process. The reconstruction of the four-stage selection procedure shows that each stage rates different features specific to training, each of them relating to specific conventions in the coordination of action. In a first step (pre-selection), the application files undergo assessment in terms of anticipated efficiency as recorded by the part-time vocational school and the companies, as well as in terms of civic criteria for furthering those who are at a disadvantage. With the standardised in-house tests, the occupational interest of the candidate is then checked as well as (again) the educational requirements of training. A third stage of selection is the face-to-face interview when the training coordinators check whether the candidate fits into the system of a training network. Of relevance here is the ability to live social relationships in a project-type world since this is what is required given the yearly rotation among the training network companies. This is a specific criterion of selection for training networks that is 
founded on the project-based convention of the organisation of training. The practical tests that are largely aligned to the requirements of the industrial, project-type and civic world of the first three stages of selection prevent a training company's discriminating calculations from the domestic and market world (social integration in company and customer bonding) asserting themselves at an early stage, such as can be observed with the placement of apprentices in small and medium-sized businesses. Only during the fourth stage, with a short placement in the training company, does the latter have the opportunity to assess a candidate's social fit in the light of companyown needs.

A number of organisational mechanisms culminate here in an only partial relevance of the social preferences of the training companies in the selection process. The following features of the apprentice placement system enable a training network that is strongly embedded in the civic world to restrict discrimination in apprentice recruitment: Firstly, the decision to be based on a choice of only two candidates, such as imposed upon the training companies, means that the latter have only a restricted scope of choice as well as chance of discrimination. From the angle of the LO, the allocation of apprentices to the companies is merely an issue of matching - unless a candidate proves himself to be untenable - and is no longer an issue of selection. Should a company reject a candidate, the training network aspires to place said person with an alternative company. It is remarkable that the companies accept this restriction, for they appreciate the problem of the LO in organising selection and indeed trust the LO to carry out this pre-selection conscientiously. Secondly, there is a clear segregation between pre-selection by the LO and the final selection by the companies, the latter having no knowledge of the application file of the candidates whatsoever, hence being unable to make generalising deductions from information on 
nationality, civic status or school reports about the domestic and market-related 'qualities' of a candidate. The company assessment of these 'qualities' tends to be based on an individualised practical test (Imdorf 2010a) under genuine company conditions. With the assessment of 'system fit', the LO also appears to largely forego collective criteria (gender, national origin). Thirdly, the responsibility to be borne by a training company for its apprentice is restricted to one training year so that a company is not so inhibited towards candidates who are considered problematic in the domestic or market-related world. For because of the principle of rotation, the risk of a difficult young adult is distributed over several companies. Fourthly, the professional support offered by the training network for difficulties with apprentices reduces the aversion to risk in terms of young adults that could harbour potential problems for a company. Fifthly, rotation during the apprenticeship is in point of fact a 'selection by instalment'; in the rare instances when a company refuses to take an apprentice in the second or third year of apprenticeship, the LO has to find an alternative solution within the network so that the apprenticeship does not have to be broken off.

A pre-selection that refrains from an early exploitation of social criteria is reminiscent of the selection procedure of a large enterprise that is directed towards the enablement of social diversity. It is remarkable that, in the case of the training network investigated, this procedure is of benefit to small companies, who tend to reproduce social homogeneity with their traditional selection processes. The switching of the organisational criterion of matching from a 'company suitability' to a 'network suitability' allows the investigated training network to fulfil its social commitment and place disadvantaged young people with smaller training companies, which are not necessarily sensitised to social interests or do not even need to have such interests at all. Even if the company requirements of the domestic and market-related world 
continue to prevail, the ability to assert selective analyses by way of the organisational mechanisms is weakened. It can, however, also be that some training companies alter their own organisational culture as a result of the positive experience acquired with a formerly problematised category of young adults and that in future it is more open towards the training of such persons.

There are two issues that merit more research to grasp the limits of the claimed anti-discriminatory recruitment procedure of training networks. On the one hand, one has to investigate whether training networks without any social commitment that organise their selection procedure in a manner similar to that of the investigated training network cope better with integrating disadvantaged school-leavers than traditionally trained occupations. It could also be that exclusively self-funded training networks without a state or para-state funding body will have to take greater account of individual companies' own prerogatives in their selection of apprentices, including the discriminatory features, because the LO is financially more dependent on the training network companies. On the other hand, the price of an egalitarian selection procedure of a training network might well be the production of a new form of disadvantaging: 'network aptitude' calls for flexibility from the young adults and the ability to live social relationships in the context of projects. The person who finds it difficult to engage permanently in new contacts and to abandon old ones is potentially vulnerable to exclusion from the networked world of a training network. The extent to which a new form of social inequality is thus generated requires further research.

Finally, we would like to share some thoughts on the theory we used to interpret our empirical findings. The sociology of conventions allows to embrace the complexity of the object of research by offering a well suited and comprehensive framework for reconstructing the most prevalent norms of apprentice selection in 
training networks and the selection criteria applied. However, the heuristic nature of this framework also has some limitations. The multiple 'worlds' that constitute work organisations are complex social constructs that are not easily measured. Thus, statistically testing the theory may pose a challenge. It requires adequate indicators for each world. Different training organisations (large firms, small companies, training networks etc.) could then be classified according to the worlds that play the most significant role in the recruitment process. Based on such a typology, one could finally test what kind of training organisation might be best suited for integrating disadvantaged school-leavers as apprentices.

\section{Notes}

1. Public discourse concerning 'foreigners' refers to the common acceptance of the notion of 'foreigner' as opposed to the concept of 'race', which has been rendered taboo in the Germanspeaking world in the wake of the National Socialist genocide (Heidenreich 2003). In contrast to the legal category of foreign nationals, the notion denotes immigrants or their descendants perceived as alien in the process of othering. The stigmatisation of being 'foreign' thereby occurs regardless of whether somebody is foreign-born or not. At present, youth referred to as 'foreigners' in Germany are mostly from families with a Turkish background or from families who immigrated from the successor countries of the Soviet Union; in Switzerland in contrast, the label 'foreigner' primarily applies to youth whose families immigrated from the successor countries of former Yugoslavia (Imdorf 2010c). In the following, we use the terms 'foreign' and 'foreigners' in quotation marks to stress the social constructedness of this category.

2. The evaluation was conducted by the author Regula Julia Leemann, together with Dr. Simone Berweger, Zurich University of Teacher Education.

3. This is a special case of one training network company: the training network sends the selected apprentices to train as electricians and IT technicans to a training workshop provided by a partner company in return for a fee.

4. As from the second year of training, with the rotation scheme, the companies are only ever recommended one single candidate.

5. Social occupations still reflect a long-rooted tradition of initially employing young people on a trainee basis before allowing them to engage in an apprenticeship.

\section{References}

BBT, Bundesamt für Berufsbildung und Technologie. 2008. Resultate Evaluation Lehrbetriebsverbünde. Bern: BBT.

Becker, G.S. 1971. The Economics of Discrimination. Second Edition. Chicago: University of Chicago Press.

BMBF, Bundesministerium für Bildung und Forschung. 2004. Berufsbildungsbericht 2004. Bonn: BMBF.

Boltanski, L. 2007. Leben als Projekt. Prekarität in der schönen neuen Netzwerkwelt. Polar no. 2: 7-13.

Boltanski, L., and E. Chiapello. 2005. The New Spirit of Capitalism. London: Verso. 
Boltanski, L., and L. Thévenot. 1999. The Sociology of Critical Capacity. European Journal of Social Theory 2, no. 3: 359-377.

Boltanski, L., and L. Thévenot. 2006. On Justification: Economies of Worth. Princeton: Princeton University Press.

DBK, DBK-Projektgruppe Verbundkonzepte. 2002. Handbuch für Ausbildungsverbünde. Bern: Schweizerisches Dienstleistungszentrum Berufsbildung.

Diaz-Bone, R. 2009. Konvention, Organisation und Institution. Der institutionentheoretische Beitrag der 'Économie des conventions'. Historical Social Research 34, no. 2: 235-264.

Dodier, N. 1993. Les appuis conventionnels de l'action. Eléments de pragmatique sociologique. Réseaux 11, no. 62: 63-85.

Eymard-Duvernay, F., and E. Marchal. 1997. Façons de recruter. Le jugement des compétences sur le marché du travail. Paris: Éditions Métailié.

Heidenreich, N. 2003. 'Deutsche' (Un-) Sichtbarkeiten. In Fremdes Begehren. Transkulturelle Beziehungen in Literatur, Kunst und Medien, ed. E. Lezzi and M. Ehlers, 307-319. Cologne: Böhlau.

Imdorf, C. 2008. Migrantenjugendliche in der betrieblichen Ausbildungsplatzvergabe - auch ein Problem für Kommunen. In Migrationsreport 2008. FaktenAnalysen - Perspektiven, ed. M. Bommes and M. Krüger-Potratz, 113-158. Frankfurt a.M.: Campus.

Imdorf, C. 2009. Die betriebliche Verwertung von Schulzeugnissen bei der Ausbildungsstellenvergabe. Empirische Pädagogik 23, no. 4: 392-409.

Imdorf, C. 2010a. Die Diskriminierung, ausländischer' Jugendlicher bei der Lehrlingsauswahl. In Diskriminierung. Grundlagen und

Forschungsergebnisse, ed. U. Hormel and A. Scherr, 197-219. Wiesbaden: VS-Verlag für Sozialwissenschaften.

Imdorf, C. 2010b. Emotions in the hiring procedure: How gut feelings' rationalize personnel selection decisions. In Emotionalizing Organizations and Organizing Emotions, ed. B. Sieben and Å. Wettergren, 84-105. Houndmills: Palgrave Macmillan.

Imdorf, C. 2010c. Wie Ausbildungsbetriebe soziale Ungleichheit reproduzieren: Der Ausschluss von Migrantenjugendlichen bei der Lehrlingsselektion. In Bildungsungleichheit revisited. Bildung und soziale Ungleichheit vom Kindergarten bis zur Hochschule, ed. H.-H. Krüger, U. Rabe-Kleberg, R.-T. Kramer and J. Budde, 263-278. Wiesbaden: VS Verlag für Sozialwissenschaften.

Jenkins, R. 1984. Acceptability, Suitability and the Search for the Habituated Worker: How Ethnic Minorities and Women Lose Out. International Journal of Social Economics 11, no. 7: 64-76.

Jewson, N., and Mason, D. 1986. Modes of Discrimination in the Recruitment Process: Formalisation, Fairness and Efficiency. Sociology 20, no. 1: 43-63.

Lee, G. and Wrench, J. 1983. Skill Seekers - black youth, apprenticeships and disadvantage. Leicester: National Youth Bureau.

Moser, U. 2004. Jugendliche zwischen Schule und Berufsbildung. Eine Evaluation bei Schweizer Grossunternehmen unter Berücksichtigung des internationalen Schulleistungsvergleich PISA. Bern: h.e.p. Verlag.

Reskin, B.F. 2003. Including Mechanisms in Our Models of Ascriptive Inequality. American Sociological Review 68, no. 1: 1-21. 
Schaub, G. 1991. Betriebliche Rekrutierungsstrategien und Selektionsmechanismen für die Ausbildung und Beschäftigung junger Ausländer. Berlin: BIBB.

Schmid, M., and M. Storni. 2004. Transition. Zur Qualifikation und Rekrutierung von Lehrlingen im Kanton Basel-Stadt. Basel: ecce gemeinschaft für sozialforschung.

Seibert, H., S. Hupka-Brunner, and C. Imdorf. 2009. Wie Ausbildungssysteme Chancen verteilen - Berufbildungschancen und ethnische Herkunft in Deutschland und der Schweiz unter Berücksichtigung des regionalen Verhältnisses von betrieblichen und schulischen Ausbildungen. Kölner Zeitschrift für Soziologie und Sozialpsychologie 61, no. 4: 595-620.

Stalder, B. 2000. Gesucht wird... Rekrutierung und Selektion von Lehrlingen im Kanton Bern. Bern: Amt für Bildungsforschung.

Strathdee, R. 2003. Vocational Education and Training and Social Capital in New Zealand. Journal of Vocational Education and Training 55, no. 1: 65-83.

Walther, B., and U. Renold (2005). Lehrbetriebsverbund - neue Chancen für Kleinund Mittelbetriebe. Die Volkswirtschaft 2005, no. 4: 39-42.

Yin, R.K. 2009. Case Study Research. Design and Methods. Fourth Edition. Thousand Oaks: Sage. 
Figure 1. Structure of a Swiss training network and the rotation of apprentices

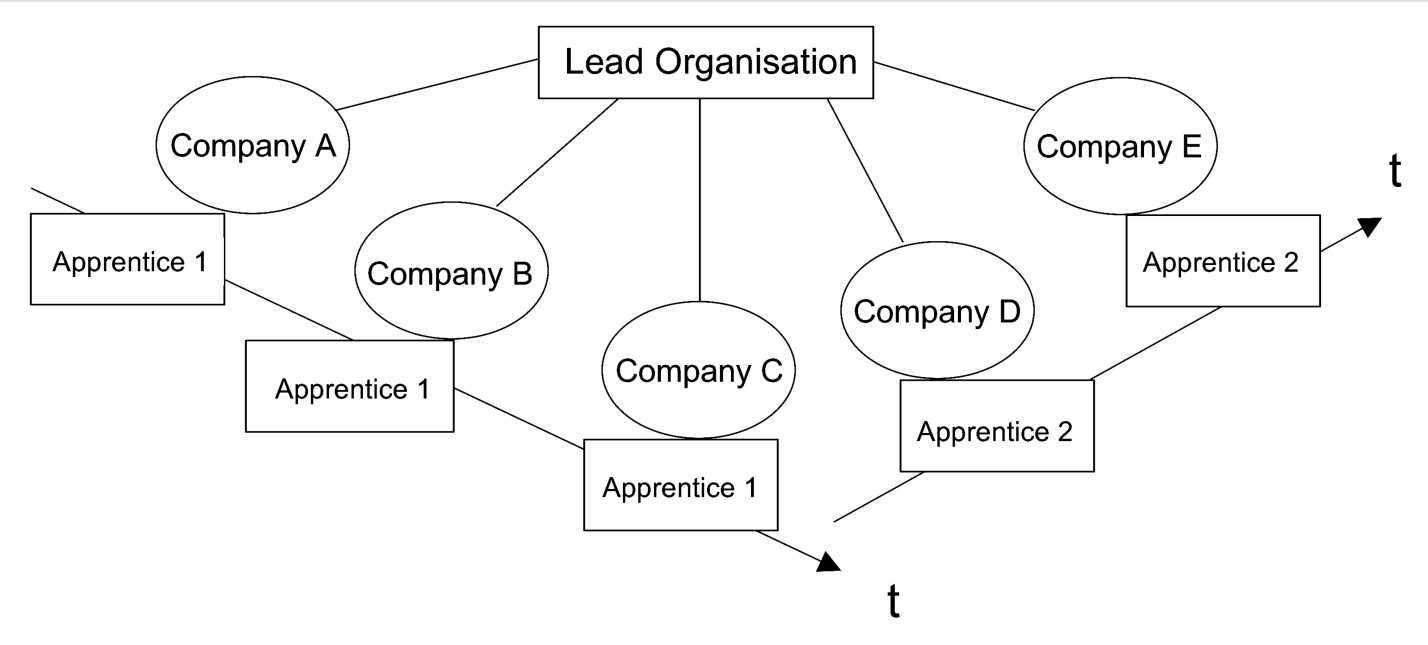

